\title{
An Interlanguage Study of Thai EFL Learners' Apology
}

\author{
Boonjeera Chiravate ${ }^{1}$ \\ ${ }^{1}$ Department of English, Faculty of Arts, Silpakorn University, Nakhon Pathom, Thailand \\ Correspondence: Boonjeera Chiravate, Department of English, Faculty of Arts, Silpakorn University, Nakhon \\ Pathom, Thailand.
}

Received: February 1, 2019 Accepted: April 15, 2019 Online Published: April 17, 2019

doi: 10.5539/elt.v12n5p116 URL: https://doi.org/10.5539/elt.v12n5p116

\begin{abstract}
Although a number of interlanguage studies on apologies have been conducted, there has been no study of apologies among Thai EFL learners that differentiates between learners with high and low levels of exposure to the target language. This study, differentiating between learners with high and low levels of exposure to the target language, addresses two research questions: (i) What are the similarities and differences between perception of offense context of Thai EFL learners and native speakers of English? (ii) What are the similarities and differences between apology strategies used by Thai EFL learners and native speakers of English? Data for the analysis came from a questionnaire consisting of 12 scenarios eliciting different offense contexts. The participants were divided into four groups: native speakers of English (NEs), native speakers of Thai (NTs), Thai EFL learners with high exposure to the target language (TEHs) and Thai EFL learners with low exposure to the target language (TELs). The results revealed that due to the influence of cultural background, the learners' perception of offense context was dissimilar to the NEs in certain respects. However, the investigation of apology strategies showed that compared to the TELs, the TEHs' apology strategies tended to be less influenced by their cultural background and more similar to the NEs'. Providing support for levels of exposure to the target language, as individual differences vary in L2 pragmatic development, the study sheds light on pedagogical intervention that may enhance learners' pragmatic competence.
\end{abstract}

Keywords: interlanguage pragmatic, speech act, politeness, apology, EFL learners

\section{Introduction}

\subsection{Introduce the Problem}

How Second/Foreign language (L2) learners acquire and use their L2 pragmatic knowledge has been one of the topics widely investigated in interlanguage studies. Focusing on speech acts, a number of interlanguage pragmatic studies examined L2 learners' knowledge of linguistic forms and cultural norms to perform different speech functions. Among the speech acts being investigated, apology has been given immense attention in recent years. However, studies investigating the influence of cultural background and how Thai learners of English as a foreign language (Thai EFL learners) differ from native speakers in ways through which an apology is carried out are limited in number. Furthermore, in none of the previous studies was learners' different levels of exposure to the target language included as part of the research design. In view of the shortcomings, the present study, differentiating between Thai EFL learners with high and low exposure to the target language, compares the perception of offense contexts and apology strategies of the learners with those of native speakers of English and examines how cultural background influences the learners' L2 pragmatic competence.

\subsection{Previous Studies}

As a background to the present study, this section summarizes the concept of speech acts (Austin 1962, Searle 1969) and politeness theory (Brown \& Levinson, 1978). Subsequently, a summary of empirical studies on apology strategies are provided.

\subsubsection{Speech Act}

Suggested by Austin (1962) and further developed by Searl (1969), speech act theory is the idea that by producing an utterance containing grammatical structures and words, people perform actions via those utterances (Yule, 1996). The actions performed can be analyzed on three levels: a locutionary act, an illocutionary act and a perlocutionary act, as demonstrated in Table 1. To illustrate, uttering the statement it's warm in here, the speaker 
not only performs the physical act of uttering the statement but may have some intention in mind such as requesting the air conditioner be turned on. Recognizing what the speaker intends, the hearer may then proceed to turn on the air conditioner. Therefore, uttering the statement, the speaker assigns his attention to such act which has an impact on the hearer.

Table 1. Dimensions of speech act

\begin{tabular}{ll}
\hline Act & \\
\hline Locutionary act & the physical act of uttering a statement \\
Illocutionary act & the intention that the speaker has assigned to such act \\
Perlocutionary act & the impact of the speaker's utterance on the hearer \\
\hline
\end{tabular}

Focusing on illocutionary act, Searle (1979) categorizes functions performed by speech acts into five categories: declaration, representatives, expressives, directives and commissives (also known as taxonomy of illocutionary acts). Revealing the speaker's psychological state, apology is considered to be one of the expressive acts. According to Blum-Kulka and Olshtain (1984), apologies are generally post-event acts signaling the fact that a violation of a social norm has been committed. By apologizing, an offender admits to the fact that he/she is at least partially involved in its cause and needs to recreate social equilibrium with the offended party (Holmes 1990).

Performing the expressive speech act of apology, both direct and indirect apologies can be used (Cohen \& Olshtain, 1983). Direct apologies generally include explicit illocutionary force indicating devices (IFID), which include performative verbs such as be sorry, apologize, or excuse. Formulaic expressions such as I'm sorry, I apologize and Excuse me are therefore direct apologies. Indirect apologies, on the other hand, do not contain an IFID (i.e. a performative verb) but may provide an explanation (e.g., The traffic was terrible), an acceptance of responsibility (e.g., It's my fault) and a promise of forbearance (e.g., I promise it won't happen again). Additionally, a combination of apology strategies with an intensifier such as terribly and really can also be used (e.g., I'm terribly sorry. I really didn't mean to keep you waiting). How a speaker phrases his/her utterance when apologizing depends on several factors as captured by politeness theory (Brown \& Levinson, 1987).

\subsubsection{Politeness Theory}

Brown and Levinson's (1987) theory of politeness is based on the concept of face. Basically, face is a public self-image of a person. A person's "face wants" involve the need to be independent (not to be imposed by others) and the need to be connected (to be treated as a member of the same group), referred to as "negative face wants" and "positive face wants", respectively. Politeness is the means employed to show awareness of another person's face. Choosing politeness strategies, a speaker evaluates many contextual factors surrounding the situation. The three most common factors affecting the politeness strategy choice are power (P), distance (D) and rank of imposition (R). It was proposed that the sum of distance between speaker (S) and hearer (H), power of the speaker and hearer and ranking of imposition determines the weight (W) of a situational context, as shown below.

$$
\mathrm{Wx}=\mathrm{D}(\mathrm{S}, \mathrm{H})+\mathrm{P}(\mathrm{H}, \mathrm{S})+\mathrm{Rx}
$$

The weight of a situational context then determines politeness strategy choice. For example, when asking someone who is not socially close to the speaker to do something that causes a large rank of imposition, the speaker usually uses politeness strategies different from when asking someone who is socially close to the speaker to do something that causes a small rank of imposition. Speakers of different cultures, however, may differ in their selection of apology strategies.

Brown and Levinson's Politeness theory has been criticized in several aspects. Leech (2007), for instance, criticized Brown and Levinson's model as Western bias and not applicable to Eastern cultures. Essentially, the concept of "face" focuses only on the individual wants in western cultures and puts aside the "group face" in eastern collectivism cultures. Despite the criticism, Brown and Levinson's Politeness theory, however, is widely used as a framework for analyzing linguistic politeness. 


\subsubsection{Empirical Studies on Apology Strategies}

\subsubsection{Apologies in English}

How native speakers of English perform the speech act of apology has been investigated in several studies including Fraser (1981), Cohen and Olshtain (1981), Olshtain and Cohen (1983), Trosborg (1987), Olshtain (1989), Keenan (1993), Meier (1996), Suszczynska (1999). Among others, Holmes' (1990) study on apology in New Zealand English has been considered as one of the cornerstone studies. Holmes investigated syntactic, semantic, and sociolinguistic features of apology in New Zealand English. Drawing a distinction between apologies in which a combination of strategies was used and those in which a single strategy sufficed, Holmes divided apology strategies into four super-strategies: explicit expressions of apology (e.g., I'm sorry, I apologize), explanation or account (e.g., The traffic was terrible), acceptance of responsibility (e.g., It's my fault) and promise of forbearance (e.g., I promise it won't happen again). Subsequently, she attempted to relate the relative weight of the offense to features of the apology strategies used to remedy it. It was found that the more serious the offense, the more elaborate the ensuing apology (Holmes 1990 as cited in Intachakra 2001: 155). Explicit expressions of apology (e.g., I'm sorry, I apologize), however, were found in almost all apology exchanges.

Additionally, a number of comparative studies such as Olshtain's (1989), Cohen and Olshtain's (1981), Olshtain and Cohen's (1983), Meier's (1996), and Suszczynska's (1999) studies compared apologies in different languages to apologies in English, illustrating how the speech act of apologizing is performed across cultures. For instance, examining language-specific apologizing behavior, Cohen and Olshtain's (1981) and Olshtain and Cohen's (1983) studies revealed that compared to speakers of American English, Hebrew speakers were less likely to use direct apologies. Instead, they would provide explanation or give reasons as to what caused the offense. Meier (1996), on the other hand, investigated apologies in American English and Austrian German. It was found that while the Americans tended to apologize effusively by giving excuses and promises of forbearance, the Austrians tended to avoid giving excuses and promises of forbearance. Similarly, Suszczynska (1999), investigating how apologies in English, Polish and Hungarian differ, found that Polish and Hungarian speakers employed requests for forgiveness and to withhold anger a lot more than English speakers, although IFIDs were commonly used in most offense contexts.

\subsubsection{Apologies in Thai}

There are two studies discussing apologies in Thai. Firstly, Makthavornvattana (1998) investigated apologizing strategies in Thai and examined the relationship between the apology strategies and offense weight. She analyzed data from 50 Thai speakers of various occupational backgrounds. Using DCT, she found that there were five super-strategies: explicit expression of apology, accepting blame, giving excuses, offering repair, and efforts to please the addressee. The strategy used at the highest frequency is explicit expression of apology, whereas giving excuses, especially the blaming of others, is the strategy used at the lowest frequency. However, apologizing strategies do not correlate with offense weight. Speakers use similar strategies, no matter how serious the offense is. Additionally, it was discussed that the speech act of apologizing illustrate an important aspect of Thai culture in which distance and power play a greater role on the type of strategy than ranking of imposition.

Another study that discusses apologies in Thai is Intachakra's (2001) study. To illustrate, his study provides a comparative analysis of three expressive speech acts (compliments, thanks and apologies) produced by native speakers of British English and Thai. Examining apologies, he adopted Holmes' (1990) classification of apology strategies to account for both British and Thai data. Comparing the display of apology in British and Thai, he classified the display of apology in British into an offer of apology (I apologize; Please accept my apologies), an expression of regret (I'm sorry; I'm afraid), a request for forgiveness (Excuse me; I beg your pardon), and classified the display of apology in Thai into general apology (kho:thô:t), formal/super deferential (khs:pratha:nt thô:t) and formal/deferential (khs:aphaj). Additionally, he further discussed linguistic structures of the speech act of apologies, the topic of apologies, interpersonal and contextual factors influencing the production of the speech act of apologies and responses given to apologies.

\subsubsection{Interlanguage Studies of Apologies}

Investigating what may potentially cause cross-cultural miscommunication between native and non-native speakers, a number of interlanguage pragmatic studies of apology focus on how L2 learners' apologies deviate from native speakers' apologies. For instance, Trosborg (1987) investigated how Danish learners of English performed the speech act of apology in English. Using role-play, Trosborg found that that in most cases, the Danes and the British did not differ much in terms of their choices of direct apology strategy. There were nevertheless several cases in which the Danes appeared to give more explanation but to offer fewer repairs (Trosborg, 1987, as cited in Intachakra, 2001). Garcia (1989), on the other hand, examined how Venezuelan 
learners of English differ from native speakers of English. Using open-ended role play, she found that the Venezuelans used more positive politeness strategies by saying something nice to express their friendliness or good feelings whereas the native speakers of English tended to use negative politeness strategies such as self-blaming.

Bataineh and Bataineh (2006), on the other hand, investigated Jordanian EFL university students' apology strategies. It was found that statements of remorse, account, compensation, promises not to repeat offense, and reparation were the apology strategies most used. Focusing on American learners of Russian, Shardakova (2009) investigated how the learners differ from native speakers of Russian in assessment of situation and apology strategy choices. Results revealed that while the natives consider all situational factors, the learners did not. However, with increasing proficiency and experience in the L2 context, the learners were found to provide more complex apology offerings in relation to situation variables. Similarly, Chang (2010), focusing on the speech act of apology, examined the pragmatic development of Chinese EFL learners with different proficiency levels. It was found that an IFID expressing regret (routine formula expressing regret) was the first strategy employed in an L2's apology repertoire. As proficiency increases, more adjuncts were found. Farashaiyan and Amirkhiz (2011), on the other hand, compared apology strategies used by Iranian EFL learners and Malaysian ESL learners with the same level of English language proficiency. Results revealed that although both groups tended to use IFID expressing regret, there were significant differences in their strategy choices due to their different cultural backgrounds.

Studies focusing on how Thai EFL learners' apologies deviate from English native speakers' apologies have been carried out by Bergeman and Kasper (1993), Thijittang (2010), and Pin-Ngern (2015). Firstly, Bergeman and Kasper (1993) compared Thai non-native speakers of English to native speakers of Thai and English in terms of how contextual factors in offense contexts are perceived and how the selection of apology strategies are determined by contextual factors. Data were collected by assessment and dialog construction questionnaires. The assessment questionnaire was completed by 30 native speakers of English and 30 Thai non-native speakers of English. The dialog construction questionnaire was completed by 30 native speakers of English, 136 native speakers of Thai and 288 Thai non-native speakers of English. Results revealed that in each of the 20 situations, native speakers of Thai and English differed in their perception of at least one contextual variable, most on the obligation to apologize and the likelihood of apology acceptance. As regards apology strategies, the Thai non-native speakers of English differed least from the native speakers of English in the use of IFID and taking on responsibility. However, it was discussed that more than half of the differences in apology suppliance can be attributed to pragmatic transfer from Thai apology patterns.

Thijittang (2010), on the other hand, investigated production of interlanguage apologies of Thai EFL learners. Data was collected by a DCT questionnaire completed by 160 Thai undergraduate students of various disciplines at a university in Thailand. It was found that the Thai EFL learners' selection of apology strategies was influenced by social status, social distance and severity of offense. Thai EFL learners tend to vary the apology patterns to match the hearer's social status. They are likely to apologize to a hearer of higher status with polite and formal forms while apologies to a hearer of equal or lower status tend to be informal and simple. The necessity for politeness also increases with social distance as Thai EFL learners' apologies were found to be most exchanged between strangers or unfamiliar people. Additionally, the more severe the offense was, the more likely for an explicit expression of apology to be accompanied by an acknowledgement of responsibility and a promise of forbearance.

Focusing on linguistic realization and metapragmatic awareness, Pin-Ngern (2015) examined Thai EFL learners' apologies. The subjects consisted of 10 Thai EFL learners with high English language proficiency and 10 Thai EFL learners with low English language proficiency. The research instrument was a Written Discourse Completion Task consisting of eight situations requiring apology, each varied in terms of situational variables. The results revealed that the learners with high and low English language proficiency were similar in using apology head act (the Illocutionary Force Indicating Devices expressing regret "I'm sorry"). Differences were found in the range of supportive moves. It was concluded that the level of English language proficiency is one factor that leads to differences in apology speech act realization in English.

Although Pin-Ngern's (2015), Thijittang's (2010) and Bergeman and Kasper's (1993) studies contributed to the body of research on Thai EFL learners' pragmatic competence, there are caveats and gaps in these studies. Collecting data from native speakers of Thai, the questionnaire Bergeman and Kasper used was in English. This could possibly cause the Thai informants to represent their perceptions of offense context in English-speaking cultures rather than in Thai culture. Thijittang (2010), on the other hand, did not include an investigation of participants' perception of offense context in her study. Moreover, neither of these studies differentiated between 
learners with high and low exposure to the target language, despite the fact that levels of exposure to the target language play an important role in L2 acquisition (Kondo, 1997; Shardakova, 2005; Shively \& Cohen, 2007)

\section{Method}

Including learners' different levels of exposure to the target language, as part of research design, the present study is conducted to investigate the perception of offense contexts and apology strategies of Thai EFL learners in comparison to those of native speakers of English.

\subsection{Research Questions}

This study addresses two research questions:

(1) What are the similarities and differences between perception of offense context of Thai EFL learners and native speakers of English?

(2) What are the similarities and differences between use of apology strategies of Thai EFL learners and native speakers of English?

\subsection{Participants}

The current study involved four groups of participants. In each group, there were 40 participants: 20 males and 20 females. The total participants were 160, as demonstrated in Table 2.

Table 2. The participants of the study

\begin{tabular}{llll}
\hline & Nender \\
\cline { 3 - 4 } & & M & F \\
\hline Native speakers of English (NEs) & 40 & 20 & 20 \\
Native speakers of Thai (NTs) & 40 & 20 & 20 \\
Thai learners of English with high exposure to the English language (TEHs) & 40 & 20 & 20 \\
Thai learners of English with low exposure to the English language (TELs) & 40 & 20 & 20 \\
\hline
\end{tabular}

The participants in the NE group were university students residing in Murray, Kentucky, USA. Those in the NT and TE (Thai learners of English) groups were Thai university students residing in Nakhon Pathom, Thailand. Based on their scores from an English language exposure questionnaire (Note 1), they were divided into TEH and TEL groups.

\subsection{Instruments}

To address the two research questions, 12 offense contexts based on Bergeman and Kasper (1993) were developed. The 12 offense contexts differ in the power (in this case, social status) of the speaker and hearer, distance between speaker and hearer and ranking of imposition, as shown in Table 3.

Table 3. Offense contexts

\begin{tabular}{llllll}
\hline & & $\mathrm{P}$ & $\mathrm{N}$ & $\mathrm{R}$ \\
\cline { 3 - 4 } & & $\mathrm{S}$ & $\mathrm{H}$ & & \\
\hline (1) & $\begin{array}{l}\text { A student plagiarizes from a published book and is } \\
\text { found out by a professor (Cheating student) }\end{array}$ & less & more & small & high \\
\hline (2) & $\begin{array}{l}\text { A and B are friends. A has had an accident with a car } \\
\text { borrowed from B. (Damaged car) }\end{array}$ & equal & & small & high \\
\hline (3) & $\begin{array}{l}\text { A professor misplaces a student's term paper and fails } \\
\text { the student. (Failed student) }\end{array}$ & more & less & small & high \\
\hline (4) & $\begin{array}{l}\text { At a restaurant, a waiter spills food on a customer's } \\
\text { clothes. (Food on customer) }\end{array}$ & less & more & large & high \\
\hline (5) & $\begin{array}{l}\text { A new neighbor broke the window. } \\
\text { (Broken window) }\end{array}$ & equal & & large & high \\
\hline
\end{tabular}




\begin{tabular}{llllll}
\hline (6) & $\begin{array}{l}\text { A customs official breaks a purchased statue when } \\
\text { searching a traveler's suitcase. (Broken statue) }\end{array}$ & more & less & large & high \\
\hline (7) & $\begin{array}{l}\text { A student forgets a book she was supposed to return to } \\
\text { her professor. (Borrowed book) }\end{array}$ & less & more & small & low \\
\hline (8) & $\begin{array}{l}\text { A and B are friends. A borrowed a pencil from B and } \\
\text { broke it. (Broken pencil) }\end{array}$ & equal & & small & low \\
\hline (9) & $\begin{array}{l}\text { A professor has not yet graded a term paper that a } \\
\text { student was supposed to pick up. (Ungraded paper) }\end{array}$ & more & less & small & low \\
\hline (10) & $\begin{array}{l}\text { At a restaurant a waiter brings the wrong order. } \\
\text { (Wrong order) }\end{array}$ & less & more & large & low \\
\hline (11) & $\begin{array}{l}\text { A new neighbor plays loud music. } \\
\text { (Loud music) }\end{array}$ & equal & & large & low \\
\hline (12) & $\begin{array}{l}\text { A customs official messes up a traveler's suitcase. } \\
\text { (Messed-up bag) }\end{array}$ & more & less & large & low \\
\hline
\end{tabular}

Note. $\mathrm{P}=$ Power; $\mathrm{D}=$ Distance: $\mathrm{R}=$ Ranking of imposition; $\mathrm{S}=$ Speaker; $\mathrm{H}=$ Hearer.

The 12 offense contexts were put in questionnaires prepared in a Thai version (for NTs) and in an English version (for NEs, TEHs, TELs). The questionnaire consisted of two parts: severity assessment and dialog construction. For the assessment part, participants were asked to rate the severity of offense contexts on a 3-point rating scale consisting of low $(\mathrm{L})$, medium $(\mathrm{M})$ and high $(\mathrm{H})$ severity. The dialog construction part takes the form of a written discourse completion task (WDCT). A sample item is provided below.

At a friend's home

John and Paul are good friends, John borrowed Paul's car for the weekend. Unfortunately, when he was backing up to park, he didn't see a lamp-post. He hit it and damaged the rear of the car. He is now returning the car to Paul.

(1) How serious is John's offense?

(2) If you were John, what would you say?

\begin{tabular}{lll}
\hline low & medium & high \\
\hline
\end{tabular}

Paul: $\quad$ Is everything okay?

John:

\subsection{Analysis}

\subsubsection{Perception of Offense Contexts}

Data from the severity assessment part was analyzed by frequency count. Across the four participant groups, the relative frequency of each offense context being assessed as low (L), medium (M) or high (H), severity was identified and calculated as a percentage. Subsequently, the severity levels assessed by the majority of each group were presented.

\subsubsection{Apology Strategies}

The data obtained from the dialog construction part was analyzed for type of apology strategies and complexity of apology strategies. First, for the type of apology strategies, data were codified based on the classification of apology strategies adopted from Holmes's (1990), Bergeman and Kasper's (1993) and Intachakra's (2001, 2004) studies, as illustrated in Table 4. Frequencies of use of each type of apology strategy are then identified. 
Table 4. Classification of apology strategies based on Holmes (1990), Bergeman and Kasper (1993) and Intachakra $(2001,2004)$

A An explicit expression of apology (IFID)

English A1 An offer of apology e.g., I must apologize; I apologize; Please accept my apologies.

A2 An expression of regret e.g., (I'm) sorry; (I'm) afraid

A3 A request for forgiveness e.g., Excuse me; Please forgive me; I beg your pardon.

Thai A1 General apology e.g., khs:thô:t

A2 Formal/super deferential apology e.g., kho:pratha:nt thô:t

A3 Formal/deferential apology e.g., khs:aphaj

B An explanation or account e.g., The traffic was terrible; There has been a lot going on in my life.

C An acceptance of responsibility

C1 Accepting the blame e.g., Silly me; It's my fault/mistake

C2 Expressing self-deficiency e.g., I'm late; I wasn't looking; I forgot

C3 Recognizing the hearer as deserving apology e.g., You're right; You deserve an apology.

C4 Expressing lack of intent e.g., I didn't mean to break it; I didn't mean to.

C5 Offering repair or showing concern e.g., I'll get a new one for you. I hope you weren't offended. Are you all right?

D A promise of forbearance e.g., I promise it won't happen again; It won't happen again.

Second, a distinction between an apology consisting of a single strategy (1 strategy) and an apology consisting of more than one strategy (i.e., 2-5 strategies) was drawn, as demonstrated in Table 5. Frequencies of occurrences of a single apology and a combination of strategies were then identified.

Table 5. Complexity of apology strategies

\begin{tabular}{ll}
\hline Number of strategies & Example \\
\hline 1 & I'm sorry. \\
& (A2) \\
& I'm sorry. I'm late. \\
& $(\mathrm{A} 2, \mathrm{C} 2)$ \\
& I'm sorry. I'm late. The traffic was terrible. \\
& (A2, C2, B) \\
& I'm sorry. I'm late. The traffic was terrible. I hope you weren't offended. \\
& (A2, C2, B, C5) \\
& I'm sorry. I'm late. The traffic was terrible. I hope you weren't offended. I promise it \\
& won't happen again. (A2, C2, B, C5, D) \\
&
\end{tabular}

\section{Results}

\subsection{Perception of offense contexts}

The four participant groups differed in their perception of offense contexts as the frequency with which they assessed the offense contexts as low, medium and high severity offense varies. In Table 6, severity levels assessed by the majority of each participant groups are presented. 
Table 6 . Severity levels assessed by the majority of the 4 participant groups

\begin{tabular}{llllllllll}
\hline & & $\mathrm{NE}$ & \multicolumn{3}{c}{$\mathrm{NT}$} & \multicolumn{3}{c}{ TEH } & \multicolumn{3}{c}{ TEL } \\
\hline$(1)$ & Cheating student & $\mathrm{H}$ & $(42.50 \%)$ & $\mathrm{M}$ & $(47.50 \%)$ & $\mathrm{M}$ & $(42.50 \%)$ & $\mathrm{M}$ & $(42.50 \%)$ \\
$(2)$ & Damaged car & $\mathrm{H}$ & $(57.50 \%)$ & $\mathrm{H}$ & $(52.50 \%)$ & $\mathrm{H}$ & $(55.00 \%)$ & $\mathrm{H}$ & $(52.50 \%)$ \\
$(3)$ & Failed student & $\mathrm{H}$ & $(40.00 \%)$ & $\mathrm{M}$ & $(42.50 \%)$ & $\mathrm{M}$ & $(42.50 \%)$ & $\mathrm{M}$ & $(40.00 \%)$ \\
$(4)$ & Food on customer & $\mathrm{H}$ & $(52.50 \%)$ & $\mathrm{H}$ & $(47.50 \%)$ & $\mathrm{H}$ & $(50.00 \%)$ & $\mathrm{H}$ & $(50.00 \%)$ \\
$(5)$ & Broken window & $\mathrm{H}$ & $(50.00 \%)$ & $\mathrm{H}$ & $(50.00 \%)$ & $\mathrm{H}$ & $(50.00 \%)$ & $\mathrm{H}$ & $(47.50 \%)$ \\
$(6)$ & Broken statue & $\mathrm{H}$ & $(55.00 \%)$ & $\mathrm{H}$ & $(52.50 \%)$ & $\mathrm{H}$ & $(55.00 \%)$ & $\mathrm{H}$ & $(52.50 \%)$ \\
$(7)$ & Borrowed book & $\mathrm{L}$ & $(42.50 \%)$ & $\mathrm{M}$ & $(45.00 \%)$ & $\mathrm{M}$ & $(42.50 \%)$ & $\mathrm{M}$ & $(45.00 \%)$ \\
$(8)$ & Broken pencil & $\mathrm{L}$ & $(62.50 \%)$ & $\mathrm{L}$ & $(57.50 \%)$ & $\mathrm{L}$ & $(60.00 \%)$ & $\mathrm{L}$ & $(57.50 \%)$ \\
$(9)$ & Ungraded paper & $\mathrm{M}$ & $(40.00 \%)$ & $\mathrm{L}$ & $(45.00 \%)$ & $\mathrm{L}$ & $(42.50 \%)$ & $\mathrm{L}$ & $(45.00 \%)$ \\
$(10)$ & Wrong order & $\mathrm{M}$ & $(45.00 \%)$ & $\mathrm{L}$ & $(52.50 \%)$ & $\mathrm{L}$ & $(47.50 \%)$ & $\mathrm{L}$ & $(50.00 \%)$ \\
$(11)$ & Loud music & $\mathrm{M}$ & $(42.50 \%)$ & $\mathrm{L}$ & $(47.50 \%)$ & $\mathrm{L}$ & $(42.50 \%)$ & $\mathrm{L}$ & $(45.00 \%)$ \\
$(12)$ & Messed-up bag & $\mathrm{M}$ & $(37.50 \%)$ & $\mathrm{L}$ & $(42.50 \%)$ & $\mathrm{L}$ & $(45.00 \%)$ & $\mathrm{L}$ & $(47.50 \%)$ \\
\hline
\end{tabular}

In Table 6, the offenses that the majority of NEs rated as high severity were Cheating student, Damaged car, Failed student, Food on customer, Broken window and Broken statue. For NTs, however, Damaged car, Food on customer, Broken window and Broken statue were rated as high severity whereas Cheating student and Failed student were rated as medium severity. Differences between NEs' and NTs' perception was also found in the Ungraded paper, Wrong order, Loud music and Borrowed book. The majority of NEs rated Ungraded paper, Wrong order and Loud music as medium severity while the majority of NTs rated these offenses as low severity. For Borrowed book, however, it was rated as low severity by the NEs but as medium severity by the NTs.

The TEHs' and TELs' perception was found to be similar. Like the NTs' rating, the majority of TEHs and TELs rated Damaged car, Food on customer, Broken window and Broken statue as high severity offenses and Cheating student and Failed student as medium severity offenses. Additionally, the majority of TEHs and TELs rated Ungraded paper, Wrong order and Loud music as low severity and Borrowed book as medium severity, like the NTs' rating.

\subsection{Use of Apology Strategies}

The dialog construction part consisting of 12 items was filled out by 160 participants, yielding 1,920 responses. However, 27 responses were non-apology such as I didn't do it (denying offending the other), You should have checked (shifting the blame onto the other). These non-apology responses were excluded, resulting in 1,893 responses. Each response consists of 1-5 occurrences of apology strategies, yielding 4,865 occurrences of apology strategies. In this section, firstly, the frequency with which each type of apology strategy was used by the four participant groups will be presented. Secondly, the frequency with which a single strategy and a combination of strategies were used by the four participant groups will be presented.

\subsubsection{Types of Apology Strategies}

The frequency with which each type of apology strategy was used by the four participant groups varied. Table 7 illustrates the percentage of each type of apology strategy used by the four participant groups in low, medium and high severity offense contexts.

Table 7. Percentage of use of apology strategies

\begin{tabular}{|c|c|c|c|c|c|c|c|c|c|c|c|c|}
\hline & & \multicolumn{4}{|c|}{$\mathbf{A}$} & \multirow{2}{*}{ B } & \multicolumn{5}{|l|}{$\mathrm{C}$} & \multirow{2}{*}{ D } \\
\hline & & & A1 & A2 & $\mathbf{A 3}$ & & C1 & $\mathrm{C} 2$ & C3 & C4 & C5 & \\
\hline \multirow{3}{*}{$\mathrm{NE}$} & $\mathrm{L}$ & $(\mathrm{n}=402)$ & 5.97 & 51.00 & 7.96 & 12.44 & 0.75 & 17.66 & 1.00 & 1.49 & 1.0 & 0.75 \\
\hline & M & $(\mathrm{n}=641)$ & 6.25 & 56.56 & 5.00 & 10.31 & 1.09 & 18.13 & 0.47 & 1.09 & 0.78 & 0.47 \\
\hline & $\mathrm{H}$ & $(n=630)$ & 6.51 & 55.56 & 4.60 & 10.63 & 1.75 & 18.57 & 0.00 & 1.27 & 0.79 & 0.32 \\
\hline
\end{tabular}




\begin{tabular}{lllllllllllll}
\hline & $\mathrm{L}$ & $(\mathrm{n}=363$ & 18.18 & 5.23 & 3.31 & 17.91 & 0.55 & 18.46 & 0.00 & 17.63 & 18.18 & 0.55 \\
$\mathrm{NT}$ & $\mathrm{M}$ & $(\mathrm{n}=493)$ & 34.48 & 5.48 & 3.04 & 14.60 & 0.00 & 13.39 & 0.00 & 14.81 & 13.79 & 0.41 \\
& $\mathrm{H}$ & $(\mathrm{n}=446)$ & 38.57 & 4.93 & 2.91 & 12.56 & 0.45 & 12.33 & 0.00 & 14.13 & 13.90 & 0.22 \\
\hline \multirow{3}{*}{$\mathrm{TEH}$} & $\mathrm{L}$ & $(\mathrm{n}=329)$ & 1.22 & 59.88 & 0.61 & 12.77 & 1.52 & 9.12 & 0.00 & 7.60 & 6.69 & 0.61 \\
& $\mathrm{M}$ & $(\mathrm{n}=445)$ & 2.02 & 60.00 & 0.45 & 11.69 & 1.57 & 10.34 & 0.45 & 5.84 & 6.74 & 0.90 \\
& $\mathrm{H}$ & $(\mathrm{n}=408)$ & 2.94 & 60.05 & 0.49 & 11.03 & 1.72 & 10.78 & 0.49 & 6.13 & 5.88 & 0.49 \\
\hline \multirow{3}{*}{ TEL } & $\mathrm{L}$ & $(\mathrm{n}=209)$ & 2.87 & 21.53 & 1.44 & 8.61 & 0.48 & 20.10 & 0.48 & 21.05 & 22.01 & 1.44 \\
& $\mathrm{M}$ & $(\mathrm{n}=266)$ & 3.38 & 39.47 & 1.50 & 4.89 & 0.75 & 18.05 & 1.13 & 15.41 & 14.29 & 1.13 \\
& $\mathrm{H}$ & $(\mathrm{n}=233)$ & 3.86 & 40.77 & 1.72 & 4.72 & 1.29 & 13.73 & 0.43 & 18.88 & 13.73 & 0.86 \\
\hline
\end{tabular}

From Table 7, the top three strategies used by NEs are A2 (expression of regret), C2 (expressing self-deficiency) and (explanation/account), regardless of severity level. For NTs, A1 (general apology), B (explanation/account), C2 (expressing self-deficiency), C4 (expressing lack of intent) and C5 (offering repair/showing concern) were used at much the same frequency in low severity offenses. In medium and high severity offenses, however, A1 (general apology) was used considerably more frequently than B (explanation/account), C2 (expressing self-deficiency), C4 (expressing lack of intent) and C5 (offering repair/showing concern). On the other hand, for TEHs, A2 (expression of regret) was used at the highest frequency followed by B (explanation/account) and C2 (expressing self-deficiency), regardless of severity level. C4 (expressing lack of intent) and C5 (offering repair/showing concern), at much the same frequency, were also used by TEHs, although not as frequent as $\mathrm{C} 2$ (expressing self-deficiency). For TELs, however, A2 (expression of regret), C2 (expressing self-deficiency), C4 (expressing lack of intent) and C5 (offering repair/showing concern) were used at much the same frequency in low severity offenses, although in medium and high severity offenses, A2 (expression of regret) was used considerably more frequent than C2 (expressing self-deficiency), C4 (expressing lack of intent) and C5 (offering repair/showing concern). Additionally, the TEs (both TEHs and TELs) were found to use B (explanation/account) considerably less frequently than C2 (expressing self-deficiency), C4 (expressing lack of intent) and C5 (offering repair/showing concern), regardless of severity level.

\subsubsection{Complexity of Apology Strategies}

Regarding the complexities of strategies, the four groups were found to differ in terms of number of strategies used in one response, as shown in Table 8.

Table 8 . Percentage of a single strategy and a combination of strategies used by the four participant groups

\begin{tabular}{|c|c|c|c|c|c|c|c|}
\hline & & & \multirow{2}{*}{$\begin{array}{l}\text { a single } \\
\text { strategy }\end{array}$} & \multicolumn{4}{|c|}{ a combination of strategies } \\
\hline & & & & 2 strategies & 3 strategies & 4 strategies & 5 strategies \\
\hline \multirow{3}{*}{ NE } & $\mathrm{L}$ & $(\mathrm{n}=115)$ & 2.61 & 13.91 & 39.33 & 38.26 & 6.09 \\
\hline & M & $(\mathrm{n}=183)$ & 4.37 & 14.75 & 38.80 & 38 & 4.92 \\
\hline & $\mathrm{H}$ & $(\mathrm{n}=180)$ & 3.33 & 16.11 & 39.44 & 38.89 & 2.22 \\
\hline \multirow{3}{*}{ NT } & $\mathrm{L}$ & $(\mathrm{n}=131)$ & 6.11 & 38.93 & 38.17 & 13.74 & 3.05 \\
\hline & M & $(\mathrm{n}=178)$ & 6.15 & 37.99 & 36.87 & 15.08 & 3.91 \\
\hline & $\mathrm{H}$ & $(\mathrm{n}=161)$ & 4.97 & 39.75 & 37.27 & 14.29 & 3.73 \\
\hline \multirow{3}{*}{ TEH } & $\mathrm{L}$ & $(\mathrm{n}=132)$ & 2.29 & 36.69 & 42.27 & 13.74 & 0 \\
\hline & M & $(n=178)$ & 2.85 & 39.98 & 45.20 & 12.99 & 0 \\
\hline & $\mathrm{H}$ & $(n=163)$ & 1.23 & 39.88 & 46.01 & 12.88 & 0 \\
\hline \multirow{3}{*}{ TEL } & $\mathrm{L}$ & $(\mathrm{n}=140)$ & 61.70 & 24.11 & 14.18 & 0 & 0 \\
\hline & M & $(\mathrm{n}=177)$ & 44.07 & 45.76 & 10.17 & 0 & 0 \\
\hline & $\mathrm{H}$ & $(\mathrm{n}=155)$ & 41.94 & 49.33 & 9.03 & 0 & 0 \\
\hline
\end{tabular}


Table 8 shows that at all levels of severity, the majority of the NEs' responses consisted of 3 or 4 strategies. Most of the NTs' responses, on the other hand, were found to consist of 2 or 3 strategies. Similar to the NTs responses, most of the TEHs' responses consisted of 2 or 3 strategies. However, most of the TELs' responses were found to be a single strategy or consist of 2 strategies.

\section{Discussion}

\subsection{Perception of Offense Contexts}

Results of the present study are compatible with Bergeman and Kasper's (1993) in several respects. The NEs' and NTs' severity ratings of Cheating student, Wrong order and Borrowed book in this study resembles Bergeman and Kasper's (1993) findings that Cheating student and Wrong order were rated as more severe by NEs than NTs whereas Borrowed book was rated as less severe by NEs than NTs. In addition, similar to Bergeman and Kasper's (1993) results NEs rated Broken statue, Failed student, Food on customer as high severity and Ungraded paper as medium severity. It was discussed that NEs considered offenses involving easily repairable inconveniences (Borrowed book) to be light offenses while those involving illegal action (Cheating student), high material costs (Broken statue) and violation of a person's physical integrity were regarded as high severity offenses. Additionally, that Failed student was rated differently by the NEs than NTs suggests that the two groups have different perspectives on professionalism and power distance. For the NEs, professionalism is expected of a professional person and negligence of professional obligation is considered to be a high severity offense. For the NTs, on the other hand, there is high power distance between teachers and students. Teachers are seen as the holders of knowledge and students' future. Consequently, the teachers' actions cannot be questioned.

Furthermore, NEs' and NTs' different ratings of Borrowed book and Broken pencil revealed cultural dissimilarity between NEs and NTs. According to Intachakra (2004: 57 as cited in Pin-Ngern 2015:50), Thailand is a hierarchy-sensitive society. Offending someone who has a higher social status is considered to be more severe than offending someone who has equal or lower social status. This is possibly why NTs rated the Borrowed book context as more severe than the Broken pencil while the NEs rated both contexts as low severity offenses. In addition, the fact that the NEs rated Failed student and Ungraded paper more severe than the NTs corroborates the difference between a collectivist society that the NTs live in and the individual culture of the NEs. This could also be an explanation for why Failed student and Ungraded paper are not necessarily severe for NTs, as long as a good relationship between the speaker (teacher) and the hearer (student) can somehow be maintained. In the same way, Loud music was rated as less severe by the NTs than by the NEs might have to do with the cultural dissimilarity. While the NEs focus on their rights being respected, the NTs focus on maintaining a good relationship between neighbors. This is also compatible with Brown and Levinson's (1987) positive face want or the need to be connected. Consequently, the NTs did not consider Loud music as severe as the NEs did.

Focusing on learners' perception of offense context, this study revealed that both the TEHs and TELs are influenced by their cultural background. As evidenced in their ratings of Borrowed book, Broken pencil, Failed student, Ungraded paper and Loud music, the learners' ratings of offense context were more similar to the NTs' than NEs'. This is congruent with results from several interlanguage pragmatic studies where L2 learners were found to transfer their L1 norms to L2. For instance, in Maeshiba et al's (1996) study of Japanese ESL learners' apologies, participants were asked to complete a metapragmatic assessment questionnaire which includes contextual factors such as social distance, social dominance and severity of offense. It was found that the ESL learners' assessment of some contextual factors was dissimilar to English native speakers due to the transfer of L1 norms (Kasper \& Rose, 2002).

\subsection{Apology Strategies}

\subsubsection{Types of Apology Strategies}

The investigation into types of apology strategies used by NEs and NTs reveals that there are both similarities and differences between them. One important similarity is that $\mathrm{C} 2$ (expressing self-deficiency) and B (explanation or account) are often included in their apology. In this study C2 (expressing self-deficiency) and B (explanation or account) ranked the second and the third among apologies strategies adopted by NEs and were included in the top five apologies strategies adopted by NTs. However, NEs and NTs differ in their use of IFIDs. A2 (expression of regret) is used at the highest frequency by NEs, regardless of severity levels of offenses. For NTs, however, A1 (general apology kho:thô:t) was not used as frequently in low severity offense contexts as in medium and high severity offense contexts. This suggests there are both similarities and differences between the two groups. The results are in line with findings from several cross-cultural pragmatic studies. For example, in Cohen and Olshtain's (1981), Olshtain's (1989) and Olshtain and Cohen's (1983) studies, both universal manifestation of strategy selection and language-specific apologizing behavior were found. It was discussed that 
compared to speakers of American English, Hebrew speakers were less likely to use direct apologies. Instead, they would provide explanation or give reasons as to what caused the offense.

One striking dissimilarity between the NEs' and NTs' apology strategies involves the use C4 (expressing lack of intent) and C5 (offering repair/showing concern). Compared to NEs, NTs were found to use C4 and C5 much more frequently. This result is consistent with Bergeman and Kasper's (1993) results. Bergeman and Kasper (1993) reported that Thai speakers often showed concern for the offended party (such as saying "I hope you weren't offended") and sometimes emphasized their lack of intent (such as saying "I didn't mean to do it"). A possible explanation is that while C5 is a way to maintain a relationship between the offender and the offended, C4 is a reflection of NTs' religious belief in which one's intention to do or not to do something is considered to be the most important thing. The NTs' preference of C4 and C5 is a language-specific apologizing behavior in line with findings from previous studies. For instance, Suszczynska (1999) found that Polish and Hungarian speakers employ request for forgiveness and to withhold anger a lot more than English speakers. Although Polish and Hungarian speakers' preferences are different from that of NTs', they can all be regarded as language-specific apologizing behavior.

Regarding the learners' use of apology strategies, this study demonstrated that A2 (expression of regret) was not used by the TELs in low severity offense contexts as frequently as in medium and high severity offense contexts. This suggests that cultural background influences the way learners use L2 to communicate. However, a comparison of the TEHs' and TELs' use of apology strategies displayed that unlike the TELs, the TEHs tended to use A2 (expression of apology) at the highest frequency regardless of severity level. Therefore, while the TELs were more influenced by their cultural background and used apology strategies less similar to the NEs, the TEHs were less influenced by their cultural background and used apology strategies more similar to the NEs, this concurs with Shardakova's (2005) results. Shardakova (2005) investigated whether exposure to the target language culture has a distinctive effect on improving pragmatic competence. American learners of Russian with high and low exposure to the target language were compared. Results revealed that the high and low exposure learners used apology strategies in a different manner. It was discussed that although the high and low exposure learners had access to the same strategies, the high exposure learners outperformed the low exposure learners in their use of apology strategies. It was concluded that levels of exposure to the target language play a significant role in how close the L2 learners perform to the target language and how their performance is influenced by their own cultural background.

\subsubsection{Complexity of Apology Strategies}

Results revealed that the four groups differ in complexities of apology strategies. Most of the NEs' responses consisted of 3 or 4 strategies. Most of the NTs' responses, on the other hand, were found to consist of 2 or 3 strategies. Similar to the NTs' responses, most of the responses from TEHs consisted of 2 or 3 strategies. However, most of the TELs' responses were found to be a single strategy or consisted of 2 strategies. Unlike most of the NEs' responses which consisted of 3 or 4 strategies, most of the TEHs' responses consisted of 2 or 3 strategies and the TELs' 1 to 2 strategies. Therefore, compared to the TEHs', responses from the TELs differ from the NEs' to a greater extent. In addition to the influence from their cultural background, this, might involve other factors including proficiency levels (Pin-Ngern 2015, Hussein \& Hammour, 1998 as cited in Alsulayyi, 2017). With their relatively lower exposure to the English language, it is likely that the TELs have relatively lower levels of English proficiency. Due to their incomplete mastery of English, the TELs therefore tended to avoid using apology strategies such as giving explanations or accounts as it might involve structures that they were not sure of (Selinker, 1972; Chang, 2010). Instead, the TELs tended to repeatedly use the formulaic expressions they well understood (e.g., expression of regret I'm sorry, expression of self-deficiency I forgot) when performing the speech act of apologizing.

\section{Conclusion}

In conclusion, this study revealed that NTs and NEs differed considerably in their perception of offense context and use of apology strategies. Focusing on Thai EFL learners, the investigation into their perception of offense context showed the learners' assessment of offense context was more like the NTs' than the NEs', suggesting that their perception of offense context was influenced by their cultural background. The further investigation into apology strategies, however, demonstrated that levels of exposure to the target language had a significant effect on the type and complexity of strategies used by the learners. Compared to the TELs, the TEHs' use of apology strategies tended to be less influenced by their cultural background and more similar to the NEs'. This suggests that in addition to cultural background, levels of exposure to the target language play an important role in L2 pragmatic development. 
Investigating the learners' pragmatic competence, this study brings into light some implications for instruction of pragmatics. According to Leech (1983), learners' pragmatic competence comprises sociopragmatics and pragmalinguistics. Allowing learners to map these two dimensions of pragmatic competence, teachers may use classroom activities which require both knowledge of linguistic forms and cultural norms. In addition to communicative practice, teachers may have students reflect on cross-cultural similarities and differences in performing certain speech acts to raise their awareness of pragmalinguistics and sociopragmatics (Ishihara \& Cohen, 2010 as cited in Youn, 2018).

Having investigated how Thai EFL learners and native speakers of English differ in their perception of offense context and apology strategies, this study has its limitations. Regarding the methodology, this study used WDCT as a research tool, because in WDCT all the situational variables were controlled and served the purpose of the study. However, although the data gained illustrated what the subjects would say and elicited the subjects' pragmatic knowledge, the data were not collected from a natural setting and lacked authenticity. Furthermore, without speaking to the participants and gathering interview data, the findings are still speculative. Additionally, this study was conducted with only 40 Thai EFL learners (20 TEHs and 20 TELs). The results may not be generalizable to all EFL learners.

Having investigated Thai EFL learners' perception of offense contexts and apology strategies in comparison to the native speakers', this study suggests that there remain several issues still to be investigated. In this study, we have concentrated on situations in which the offense is known to both the hearer and the speaker. Cases where a violation has not yet been committed or where the hearer is not as yet aware of it (e.g., I'm sorry to bother you, but can I ask for a pen or something?) needs further investigation. Moreover, in addition to levels of exposure to the target language, further studies are needed to investigate how other individual differences such as age, gender and motivation (Kasper \& Rose 2002) play a role in L2 pragmatic development. How these individual differences effect the way learners perform certain speech acts awaits future research.

\section{References}

Alsulayyi, M. (2007). A contrastive study of the use of apology strategies by Saudi EFL Teachers and British native speakers of English: A pragmatic approach. International Journal of English Linguistics, 7(1), 45-57. https://doi.org/10.5539/ijel.v7n1p45

Austin, J. L. (1962). How to do things with words. Oxford: Oxford University Press.

Bataineh, R. F., \& Bataineh, R. F. (2006). Apology strategies of Jordanian EFL university students. Journal of Pragmatics, 38(11), 1901-1927. https://doi.org/10.1016/j.pragma.2005.11.004

Bergeman, M., \& Kasper, G. (1993). Perception and performance in native and nonnative apology. In G. Kasper, \& S. Blum-Kulka (Eds.), Interlanguage Pragmatics (pp. 82-107). Oxford: Oxford University Press.

Blum-Kulka, S., \& Olshtain, E. (1984). Request and apologies: A cross-cultural of speech act realization patterns (CCSARP). Applied Linguistics, 5, 196-213. https://doi.org/10.1093/applin/5.3.196

Brown, P., \& Levinson, S. (1978). Politeness: Some universals in language usage. Cambridge: Cambridge University Press.

Chang, Y. F. (2010). I no say you say is boring: the Development of pragmatic competence in L2 apology. Language Sciences, 32, 408-424. https://doi.org/10.1016/j.langsci.2009.07.002

Cohen, A., \& Olstain, E. (1981). Developing a measure of sociocultural competence: The case of apology. Language Learning, 31, 113-134. https://doi.org/10.1111/j.1467-1770.1981.tb01375.x

Cohen, A., \& Olshtain, E. (1983). Apology: A speech act set. In Wolfen, \& E. Judd (Eds.), Sociolinguistics and language acquisition (pp. 18-35). Rowley, MA: Newbury House.

Cohen, A., \& Shively, L. R. (2007). Acquisition of request and apologies in Spanish and French: Impact of study abroad and strategy-building intervention. The Modern Language Journal, 91, 190-212. https://doi.org/10. 1111/j.1540-4781.2007.00540.x

Farashaiyan, A., \& Amirkhiz, S. Y. Y. (2011). A descriptive-comparative analysis of apology strategies': The case of Iranian EFL and Malaysian ESL university students. English Language Teaching, 4, 224-229. https://doi.org/10.5539/elt.v4n1p224

Fraser, B. (1981). On apologizing. In F. Coulmas (Ed.), Conversational Routine: Explorations in standardized communication situations and prepatterned speech (pp. 258-271). The Hague: Mouton. https://doi.org/10. $1515 / 9783110809145.259$ 
Garcia, C. (1989). Apologizing in English: Politeness strategies used by native and non-native speakers. Multilingua, 8(3). https://doi.org/10.1515/mult.1989.8.1.3

Holmes, J. (1990). Apologies in New Zealand English. Language in Society, 19, 155-199. https://doi.org/10.1017/s0047404500014366

Hussein, R. F., \& Hammour, M. T. (1998). Strategies of apology in Jordianin Arabic and American English. Gazer Linguistische Studien, 49, 37-51.

Intachakra, S. (2001). Linguistic politeness in British English and Thai: A comparative analysis of three expressive speech acts (Unpublished doctoral dissertation). University of London, England.

Intachakra, S. (2004). Contrastive pragmatics and language teaching: Apologies and thanks in English and Thai. RELC, 35, 37-62. https://doi.org/10.1177/003368820403500105

Ishihara, N., \& Cohen, A. (2012). Teaching and learning pragmatics: Where language and culture meet. The Modern Language Journal, 96(2), 330-332. https://doi.org/10.1111/j.1540-4781.2012.01348.x

Kasper, G., \& Rose, S. (2002). Pragmatic development in a second language. Language Learning, 52(supp1), 1-339. https://doi.org/10.1111/j.1467-1770.2002.tb00022.x

Keenan, S. (1993). Investigating deaf students'apologies: an exploratory study. Applied Linguistics, 4, 364-381. https://doi.org/10.1093/applin/14.4.364

Kondo, S. (1997). The development of pragmatic competence by Japanese learners of English: Longitudinal study on interlanguage apologies. Sophia linguistica, 41, 265-284.

Leech (1983). Principles of pragmatics. London: Longman.

Leech, G. (2007). Politeness: Is there an east-west divide? Journal of Politeness Research. Language, Behaviour, Culture, 3(2), 167-206. https://doi.org/10.1515/PR.2007.009

Maeshiba, N., Yoshinaga, N., Kasper, G., \& Rose, S. (1996). Transfer and proficiency in interlanguage apologizing. In S. M. Gass, \& J. Neu (Eds.), Speech acts across cultures: Challenges to communication in a second language (pp. 155-187). Berlin: Mouton de Gruyter. https://doi.org/10.1515/9783110219289.2.155

Makthavornvattana, T. (1998). The speech act of apologizing in Thai (Unpublished master thesis). Chulalongkorn University, Thailand.

Meier, A. (1996). Two cultures in repair work. Multilingual Journal of Cross-cultural and Interlanguage Communication, 15, 149-170. https://doi.org/10.1515/mult.1996.15.2.149

Moedhiran, P. (2005). Corretion making among Thais and Americans: A study of cross-cultural and interlanguge pragmatics (Unpublished doctoral dissertation). Chulalongkorn University, Thailand.

Olshtain, E. (1989). Apologies across languages. In S. Blum-Kulka, J. House, \& G. Kasper (Eds.), Cross-cultural pragmatics: Requests and Apologies (pp. 155-173). Norwood, NJ: Ablex Publishing Corporation.

Olshtain, E., \& Cohen, A. (1983). Apology: A speech act set. In N. Wolfson, \& E. Judd (Eds.), Sociolinguistics and language acquisition (pp. 18-35). Rowley, MA: Newburry House.

Pin-Ngern, A. (2015). Thai EFL learners' apology speech act realization. Asian International Journal of Social Sciences, 15(2), 34-55. http://doi.org/10.29139/aijss.2015203

Pongprairat, R. (2011). A Study of interlanguage English intonation in Thai learners, and the degree of interlligibility and comprehensibility in native speaker's judgments (Unpublished doctoral dissertation).

Searle, J. (1969). Speech acts: an essay in the philosophy of language. Cambridge: Cambridge University Press. https://doi.org/10.1017/CBO9781139173438

Searle, J. (1979). Expression and meanings: Studies in the theory of speech acts. New York: Cambridge University Press. https://doi.org/10.1017/CBO9780511609213

Selinker, L. (1972). Interlanguage. Interlanguage Reiew of Applied Linguistics in Language Teaching, 10(3), 209-321. https://doi.org/10.1515/iral.1972.10.1-4.209

Shardakova. (2005). Intercultural pragmatics in the speech of American L2 learners of Russian: Apologies offered by Americans in Russian. Intercultural Pragmatics, 2, 423-451. https://doi.org/10.1515/iprg.2005. 2.4.423

Shardakova, M. (2009). Interlanguage Pragmatics of the Apology: How Americans Acquire Sociolinguistic Competence in Russian. USA, VDM Veriag Dr. Muller. 
Shively, R., \& Cohen, A. (2007). Acquisition of Requests and Apologies in Spanish and French: Impact of Study Abroad and Strategy-Building Intervention The Modern Language Journal, 91(2), 189-212. https://doi.org/10.1111/j.1540-4781.2007.00540.x

Sudasna Na Ayudhya, P. (2002). Models of mental lexicon in bilinguals with high and low second language experience: an experimental study of lexical access (Unpublished doctoral dissertation). Chulalongkorn University, Bangkok.

Suszczynska, M. (1999). Apologizing in English, Polish and Hungarian: different languages, different strategies. Journal of Pragmatics, 31, 1053-1065. https://doi.org/10.1016/s0378-2166(99)00047-8

Thavorn, S. (2011). The interpretation of syntactic ambiguity in English sentences by Thai students with high and low English language experience (in Thai) (Unpublished master's thesis). Chulalongkorn University, Bangkok.

Thijittang, S. (2010). A study of pragmatic strategies of English of Thai university students: Apology speech acts (Unpublished doctoral dissertation). University of Tasmania, Australia.

Trosborg, A. (1987). Apology strategies in native/non-natives. Journal of Pragmatics, 11, 147-167. https://doi.org/10.1016/0378-2166(87)90193-7

Wongaram, P. (2011). A comparison of strategies and errors of Thai students with different English language experience in the formation of English words equivalent to Thai compounds (in Thai) (Unpublished master's thesis). Chulalongkorn University, Bangkok.

Worathumrong, S. and Luksaneeyanwin, S. (2016). Interlanguage pragmatics study of compliments among Thai EFL learners. Journal of Pan-Pacific Association of Applied Linguistics, 20(1), 157-182.

Yule, G. (1996). Pragmatics. Oxford: Oxford University Press.

Youn, S. J. (2018). Second language pragmatics. In A. Phakiti (Ed.), Palgrave handbook of applied linguistics research methodology (pp. 829-844). Basingstoke: Palgrave Macmillan. https://doi.org/10.1057/978-1137-59900-1_38

\section{Notes}

Note 1. The English language exposure questionnaire, developed by scholars from Centre of Research in Speech and Language Processing (CRSLP), Chulalongkorn University since 2002, has been proven in many research studies (including Sudasna Na Ayudhya 2002; Modehiran, 2005; Thavorn 2011; Wongaram 2011; Pongprairat 2011, Worathumrong \& Luksneeyanawin 2016) to clearly differentiate between learners with high and low exposure. The questionnaire comprises 3 parts with a total score of 333. Part I (116 points) concerns English language proficiency from past until present and information about English language experience and the amount of exposure at home and school. Part II (100 points) concerns education, extra curriculum and English self-practice activities. Part III (117 points) concerns intensive English language exposure. In this study, the inferential statistic of the scores in all parts of the questionnaire reveals that the exposure level of the TEH group was significantly higher than that of the TEL group.

\section{Copyrights}

Copyright for this article is retained by the author(s), with first publication rights granted to the journal.

This is an open-access article distributed under the terms and conditions of the Creative Commons Attribution license (http://creativecommons.org/licenses/by/4.0/). 